combining the effects of exercise and isoprenaline he has derived an index of lability which gives an indication of how much the airways resistance, and probably the calibre of the bronchi, are likely to vary from time to time in an individual patient. On the basis of lability index he divides his patients into three groups: those with slightly reduced resting F.E.V..$_{1}$ and a slightly increased lability ; those with a slightly reduced resting F.E.V. ${ }_{1}$ but a greatly raised lability; and those with a much reduced resting F.E.V..$_{1}$ and very variable amount of lability. The full clinical significance of this grouping has yet to be worked out in practice, but it certainly serves a useful purpose in drawing attention to the great differences between different asthmatic children. Perhaps the greatest usefulness of the lability index will come in assessing the likely response to treatment and in detecting the chronic asthmatic.

An ever-present problem in the management of asthma in childhood lies in prognosis. Most patients experience a great improvement at puberty, perhaps related to their pubertal growth spurt. But in some children the asthma persists, and in others it recurs after a variable latent period which may last for many years. ${ }^{5}$ How can the physician predict which patients are likely to recover completely at puberty and which are liable to relapse ? How many adult patients with bronchitis and chronic respiratory insufficiency are former childhood asthmatics who have experienced a latent phase ?

The answer to these questions must come from the study of the latent phase in asthma. Drs. R. H. Trefor Jones and R. S. Jones describe (at p. 976 this week) a finding which may be very useful in detecting which asthmatics remain susceptible to further trouble, although symptom-free at the time. Apparently a fall in F.E.V..$_{1}$, sometimes rather large, takes place on exercise in adults with a history of childhood asthma. It remains to be seen how much prognostic significance should be attached to this finding. At the very least a means has been found of detecting an abnormality during this latent phase of asthma. Perhaps factors other than exercise will now be found which affect ventilatory function in a similar way during this phase. Study of these factors may begin to tell us why the remission does not always last, and how to prevent relapse.

The discovery that the bronchi remain abnormally susceptible, like the persistence of eosinophilia during remissions, reinforces the impression derived from the strong family pattern of the disease that asthma is primarily an inborn defect, the expression of which at any one time depends on environmental and psychological circumstances.

\section{Unemployment and Suicide}

To lose his job is one of the greatest blows that can befall a man. Many are likely to have this experience as a result of the measures which the Government considers necessary for the country's economic salvation. Is our country adequately prepared to minimize the harm that these actions taken for its collective well-being may do to the individual ?

Though obvious difficulties surround any attempt to measure the effect on a person's health of prospective or actual

\footnotetext{
Cobb, S., Brooks, G. W., Kasl, S. V., and Connelly, W. E., Amer. 7. publ. Hlth, 1966, 56, 1476.

2 East, W. N., F. ment. Sci., 1913, 59, 528.

3 Ewinscow, D., Brit. med. F., 1951, 1, 1417.

- Sainsbury, P., Suicide in London, 1955, Maudsley Monograph No. 1. London.

stengel, E., and Cook, N. G., Attempted Suicide, 1958, Maudsley Monograph No. 4. London.
}

C unemployment, a long-term study of this kind has been started in the U.S.A. and is the subject of a recent report ${ }^{1}$ that goes no further so far than describing the methodology. The persons being studied are male factory workers in Michigan who are married and have at least three years' seniority. The main cause of their unemployment appears to be the introduction of automation into the factories. Clearly this must have a bearing on the British scene, for automation is coming here just as it already has, to a more advanced degree, in the U.S.A. Consequently the results of this study will be awaited with great interest.

That unemployment may be an important cause of suicide was a conclusion W. Norwood East ${ }^{2}$ reached after studying some statistics for the years 1903-12 in England and Wales. The statistics for unemployment were at that time very incomplete. Better figures became available later, and D. Swinscow ${ }^{3}$ used these to show a remarkably close relationship from 1923 to 1947 between numbers of suicides and numbers of unemployed among the male population of Great Britain. The correlation ratio in fact was +0.93 . He concluded that " unemployment among men, or the society of which it is a feature, probably influences the suicide rate among men considerably." The corresponding statistical relationship was much less close for females. A study of suicide in London by $\mathrm{P}$. Sainsbury ${ }^{4}$ showed a higher rate among unemployed than employed people, and the case reports suggested that loss or lack of employment predisposed to suicide. The author also considered that "both suicide and unemployment are separate consequences of a common cause-a general social disturbance."

The causes of suicide in a multifarious society like ours are certainly highly diverse, and in a single individual may be complex, ${ }^{5}$ so that unemployment in itself when present as part of the cause may be acting very indirectly. It is also possible that mentally infirm people are more apt to lose their jobs in times of social upheaval than their more stable brethren. In any case the coming months will impose strains on individual patients that medical men may be able to detect and mitigate.

\section{Chicken-pox Pneumonia}

Though chicken-pox is usually a benign disease, its lesions in some viscera can occasionally cause serious trouble. ${ }^{1}$ A. F. Knyvett ${ }^{2}$ has recently given a report on pulmonary lesions. The liver, adrenal glands, and spleen may all be attacked, and in 1940 H. N. Johnson ${ }^{3}$ gave a detailed necropsy report of disseminated chicken-pox. In $1942 \mathrm{~J}$. J. Waring and his colleagues ${ }^{4}$ gave the first report of lesions in the lung, and by 1963 upwards of 120 cases of chicken-pox pneumonia had been reported. J. B. Mackay and P. Cairney have reported nodular pulmonary calcifications thought to be due to chicken-pox suffered in earlier adult life, and E. W. Abrahams and his colleagues ${ }^{6}$ have described calcification developing seven years after primary chicken-pox pneumonia.

In primary chicken-pox pneumonia the condition of the patient (who is more often adult than child) may after several uneventful days deteriorate. Pleuritic pain, cough, and

\footnotetext{
Brit. med. ₹., 1965, 2, 954.

Knyvett, A. F., Quart. F. Med., 1966, 35, 313.

4 Waring, J. J., Neubuerger, K., and Geever, E. F., Arch. intern. Med., $1942,69,384$

5 Mackay, J. B., and Cairney, P., N.Z. med. F., 1960, 59, 453.

Abrahams, E.'W., Evans, C., Knyvett, A. F., and Stringer, R. E., Med. f. Aust., 1964, 2, 781.
} 
shortness of breath develop, with shock and cyanosis, ending in about $20 \%$ of cases in coma and death. In the chest radiograph shadows from several millimetres to more than a centimetre in diameter are bilaterally and extensively distributed, with the lung apices perhaps spared. But despite widespread shadows the patient's general condition may be good. When the lungs are affected clinical resolution usually occurs within two to three weeks and radiological resolution within eight, though some shadows may persist for months or years.

At necropsy papular lesions are found, with central haemorrhage on the pleura and foci of haemorrhage and consolidation 2-3 $\mathrm{mm}$. in diameter or perhaps confluent. The nodules in the lungs are discrete, an outer layer of fibrous tissue enclosing necrotic material, with a varying amount of calcium ; or within a capsule of circularly disposed fibrous tissue the nodule may be composed of collagen or hyaline with little orientation. The hyaline may be mixed with caseous material, and Knyvett suggests that the fibrosis proceeds through hyalinization to caseation and calcification, though, as he says, the usual pattern would be for caseation to occur first. Microscopically, focal necrosis and haemorrhage are seen, with infiltration by macrophages, lymphocytes, and polymorphs. The walls of small blood vessels may be affected and intranuclear and intracytoplasmic inclusion bodies seen. Numerous calcified opacities, usually about $2 \mathrm{~mm}$. in diameter, may years later be seen to have developed in the lungs, the earliest two years after the acute illness. No clinical or pathological evidence of tuberculosis or histoplasmosis has been found.

The lesions are sufficiently characteristic for pathologist, radiologist, and clinician to make the diagnosis in these cases. But in some cases it may be possible to complete the story by identifying the virus in material from the lung if it is deep-frozen and unfixed.

\section{Training of Hospital Junior Staff}

The current ferment among hospital junior staff goes deeper than discontent over long hours and meagre pay. These young men know they need the opportunity to continue learning if they are to advance in their profession, and present working conditions in many hospitals are far from conducive to the pursuit of knowledge. It can be argued that the preregistration houseman should be encouraged to learn from the practical application of knowledge gained in medical school, but the senior house officer and registrar, committed to higher examinations, need adequate time off for study. Many regional hospitals accept this, and do their best to provide facilities for staff in training. By doing so they reap benefits by attracting men and women of high calibre. But the success of training schemes depends on active support by senior staff, and it is not only junior hospital staff who are hard pressed. Time is at a premium for all who work in the hospital service.

An admirable report on training facilities for junior hospital staff in the Glasgow region by Sir Charles Illingworth ${ }^{1}$ exposes many of the difficulties in postgraduate medical education in Britain today. For the young doctor hospitals must provide more than practical training; they must also

\footnotetext{
Illingworth, Sir Charles. Training Facilities for funior Hospital Staff, 1966. Glasgow Postgraduate Medical Board.

: Paton, A., Postgrad. med. F., 1966, 42, 100.

: Paton, A., Postgrad. med. 7., 1966, 42,
}

produce future teachers and raise standards of medical care by offering facilities for study, travel, and research. Normal conditions of hospital work should include regular staff meetings, unit conferences, and other educational programmes, which junior staff should attend as a matter of course. "A hospital where doctors visit and tend their patients and depart may give adequate routine care but can provide little stimulus for those in training. A progressive hospital must offer opportunities for argument, discussion, and debate." In addition junior staff should be allowed adequate time off to attend educational activities elsewhere, a practice which is being increasingly accepted. ${ }^{2}$ In many parts of the country these types of facilities already exist; the problem still remains of how overburdened junior staff are to use them. For example, Sir Charles found that, while hours of work in peripheral hospitals were reasonable, staff in hospitals in the city were often overworked and much of the work was routine and devoid of educational value. Too much time was spent on secretarial work and on tasks which could have been done by non-medical staff. A complete reappraisal of the work that junior staff should be expected to undertake might free them for a reasonable amount of educational activities, and Dr. S. K. Sarkar's plea in our correspondence columns this week (page 1011) echoes the thoughts of many young doctors.

Another problem about which the Glasgow report has much to say is the present haphazard progress up the specialist ladder. Many registrars would probably welcome some form of organized training scheme, ${ }^{3}$ though obviously too rigid a pattern is to be avoided. A plan extending over several years would not only offer the trainee specialist some security but would also allow of rotation between general and special units and between centre and periphery. Married quarters would have to be provided. The time is passing when the intending specialist can afford to try his luck. He needs practical help. Only if it is forthcoming will the hospital service continue to attract candidates of the highest quality.

\section{Current Practice}

No doctor likes to feel out of date, but knowledge is advancing so fast and on so many fronts that the task of keeping up becomes increasingly daunting. The Current Practice section of the B.M.F. is designed to pick out the fields in which the advances are of practical importance to doctors treating patients and to give sound advice on the application of this new knowledge. This week at page 993 is the first article of a series on the management of skin disease. All doctors in hospital and general practice learn to recognize the common disorders of the skin, but in the last few years antibiotics, specific fungicides, and topical corticosteroid preparations have revolutionized treatment. The articles are limited to management and will touch only lightly on diagnosis, but will give a critical assessment of the newer remedies. No attempt is being made to present a comprehensive account of dermatology, and rare disorders will not be discussed.

Next month the articles on Today's Drugs will be resumed. Each year many new drugs are released, but few become established as of lasting value. Accounts will be given of the newcomers that prove to have real advantages in efficacy or in freedom from the adverse effects of their predecessors. 